\title{
Lifecycle Design of Fastening Systems in Concrete Supported by BIM: Case Study Subsequent Assembly of an Industrial Robot
}

\author{
Panagiotis Spyridis ${ }^{\mathrm{a}^{*}}$, Marvin Hoepfner ${ }^{\mathrm{a}}$, Mike Gralla ${ }^{\mathrm{b}}$, Lisa Theresa Lenz ${ }^{\mathrm{b}}$, Kai Christian Weist ${ }^{\mathrm{b}}$ \\ ${ }^{a}$ Chair of Fastening Technology, Department of Architecture and Civil Engineering, TU Dortmund University, August-Schmidt-Straße 8, \\ Dortmund 44227, Germany \\ ${ }^{b}$ Chair of Construction Management, Department of Architecture and Civil Engineering, TU Dortmund University, August-Schmidt-Straße 8,
}

Dortmund 44227, Germany

\begin{abstract}
In the last years, particular focus has been devoted to the life cycle performance of fastening systems, which is reflected in increasing numbers of publications, standards, and large-scale research efforts. Simultaneously, experience shows that in many cases, where fastening systems are implemented - such as industrial facilities - the design of fasteners is governed by fatigue loading under dynamic characteristics. In order to perform an adequate design and to specify the most efficient and appropriate fastening product, the engineer needs to access and process a broad range of technical and commercial information. Building Information Modeling (BIM), as a data management method in the construction industry, can supply such information and accommodate a comprehensive design and specification process. Furthermore, the application of BIM-based processes, such as the generation of a BIM-model, allows to use the important information for the construction as well as the life-cycle management with different actions and time dependencies of the asset and its components. As a consequence, the BIM model offers the potential to correlate different data relevant for achieving the goals of the respective application, in order to ensure a more effective and correct design of the fastening. This paper demonstrates such a BIM-based design framework for an Industry 4.0 case, and in particular, the installation of a factory robot through post-installed anchors under fatigue relevant loading in concrete.
\end{abstract}

(C) 2019 The Authors. Published by Budapest University of Technology and Economics \& Diamond Congress Ltd.

Peer-review under responsibility of the scientific committee of the Creative Construction Conference 2019.

Keywords: Building Information Modeling; Fastening Systems; Fatigue Loading; Industry 4.0; Lifecycle Design;

\section{Introduction}

Building information modelling (BIM) is vividly gaining scope of application in the construction industry, which is evident in numerous publications of academic studies, case studies, national and industry standards, and in dedicated technical events. BIM presents a variety of benefits in several aspects of infrastructure engineering, most eminently with respect to project coordination during the planning and construction phase, and the facility management during building operation. The privilege of relying on BIM for the life cycle management of technical assets is currently a focus in the discourse of digital planning and construction. In particular, archived BIM models can accommodate efficient processes for locating the component of interest, evaluating it's remaining service life, assessing costs of 
Spyridis et al. / Proceedings of the Creative Construction Conference (2019) 117

https://doi.org/10.3311/CCC2019-117

maintenance or replacement, and coordinating inspection and maintenance exercises at a project level. Modern industry currently begins to support dynamic interactions between the digital and hardware or built environment (e.g. IoT systems), based on a combination of live multidimensional BIM models connected in a network of data transfers and processing. Recently, research in the field [1], [2] has achieved to transfer building facility management exercises to the Industry 4.0 realm, by coupling building with factory operation datasets, thus opening the potential for further integration of various technical and industry disciplines to multidimensional BIM objects [3].

At the same time, connections and fastenings are a key element in the construction sector. As a critical and repetitively used component in construction, fasteners, are required to exhibit a consistent life cycle with the respective fixture. Sensitivities to a fastening system's life-cycle performance are associated among other to assembly/decommission flexibility, accessibility, load-bearing capacities under dynamic, seismic, or sustained loads, and environmental specifications such as thermal and noise insulation, fire resistance, material resources [4]. Human errors at installation are very common and they can consume even the entire load-bearing capacity of the fixing, well before the intended end of service life. The potential loss due to system losses caused by failed fastening elements is by several orders of magnitudes higher than the value of the product itself. Therefore, for structural connections, the entire structure's design service life must be maintained also for fastenings and for attachments of technical equipment, performance of the fastening is essentially a precondition for the operation of the equipment. Highly significant attachments are those associated to human life and safety (lifeline equipment, suspended building furniture, etc.), or to a substantial economical value (such as machines or robots in factory production lines). This study focuses on this latter case, and it presents a life-cycle approach of fastenings in the environment of modern automatised industry production.

In particular, this case study highlights the relevance of BIM modelling for an improved design and life cycle assessment of fastenings. The concept is presented in terms of an Industry 4.0 case study, with focus on the foundation of a robotic arm susceptible to fatigue failure. Factors significant for the short-term and fatigue design of the fastening are extracted from an enhanced BIM object, where both building as well as operational data are stored [5]. The necessary input data are described, they are converted into compliant forms, and they are used for a structural design based on realistic actions on the fastening. Moreover, the flow of live information is used for an effective prediction of the fastening's service life, allowing for an educated maintenance strategy. In parallel, this study demonstrates a holistic use of BIM in operating Industry 4.0 components, coupling production and building management of factory assets.

\section{Structural characterization and designing of fastening systems}

For the structural dimensioning of fastening systems, designs procedures are carried out according to currently valid models in the standards. The newly issued Eurocode for fastenings, EN 1992-4 [6], is the applicable reference standard in Europe and largely implemented worldwide.

The structural design is typically done on the basis of action and resistance, i.e. assessment and comparison between the properties of the fastening system and the performance requirements. Actions are typically categorised through the following aspects:

- Mechanical action types (quasi-static action, fatigue relevant action, seismic action, temperature, etc.)

- Temporal course, values of the action and behaviour of the load

- Geometric direction of action (axial, transverse)

As regards fastening system properties, the following elements must be accounted:

- Fastening group or individual fastening

- Geometry (edge distances, spacing between fasteners, fastener diameter, embedment depths, etc.)

- Materiality of fastening (concrete class, mortar, plastic sleeves, steel class, etc.)

- Mechanical resistance and load transfer mechanism (friction, bonding, mechanical interlock) 
Spyridis et al. / Proceedings of the Creative Construction Conference (2019) 117

https://doi.org/10.3311/CCC2019-117

The performance of the system is mainly described in a publically controlled product specification, the so called European Technical Assessments (ETA), and it is also officially guaranteed thereof. This document generally includes the products material and geometry, the setting procedure, geometric boundary parameters and the final mechanical resistances [7].

The mechanical actions can be quasi static, dynamic (fatigue-relevant, seismic, impact), or a random combination thereof. The fatigue-relevant actions, respective non-resting actions, upon which this case study concentrates, are subdivided into different components, depending on their time-history, whereby periodic and harmonic functions typically resulting, for example as the effect of unbalances of rotating machines [8]. Above all, the identification and differentiation of fatigue-relevant loads and the level of simplification of the motion and load history has a substantial effect on the design, i.e. the utilisation and economic efficiency in combination with the lifetime analysis. Especially in the case of fastening robots, which can deliver an exact, three-dimensional load and force profile, the conventional approach of sinusoidal independent functions has its limits in terms of feasibility and economic efficiency. Detailed considerations and associated calculation paradigms, accounting for an aggregation of multiple simultaneous loading data, are shown in the following chapters using the case of the fastening of a robot.

\section{Building Information Modelling (BIM)}

A BIM is a digital representation of physical and functional characteristics of a facility. As such it serves as a shared knowledge resource for information about a facility forming a reliable basis for decision during its lifecycle from inception onward. If implemented, nearly every piece of information that an owner needs about a facility throughout its life can be made available electronically. As Fig. 1 illustrates, the BIM method is separated from conventional planning methods at the point from planning in three dimensions by using just geometric data to three dimensions combined with other information e.g. data like quality information or maximum loads. At this stage it turns from a building model to a building information model, where information about time and costs are associated into the fourth and fifth dimension.

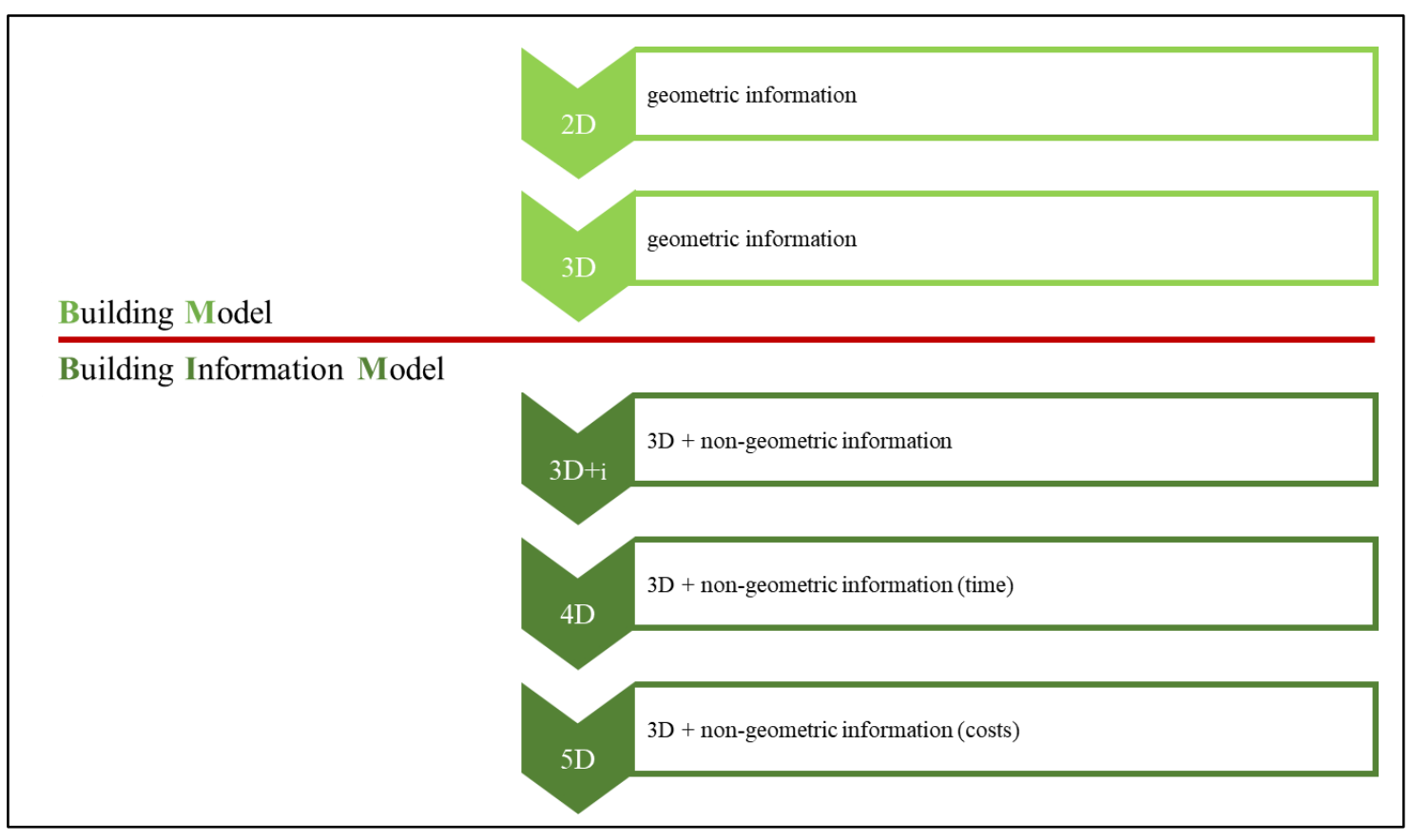

Fig. 1. Building Information Modelling vs. conventional planning. 
Spyridis et al. / Proceedings of the Creative Construction Conference (2019) 117

https://doi.org/10.3311/CCC2019-117

\section{Data utilization for life cycle design}

In order to determine whether there are efforts by using data it is necessary to examine the existing data base of the several parts. This section describes a case study with three different objects of investigation (robotic arm, fastening system, building slab) as illustrated in Fig. 2. Table 1 summarises the relevant data from the BIM model, for every different module.

The floor slab was created within a BIM-Model, as a main module with six submodules. The submodules are: coating system, concrete floor slab, sealing, smoothing layer, base, and underground. By designating the individual submodules, it is possible to filter out data from a higher number of influencing and relevant information, and to localize dependencies between all further modules and sub-modules. Furthermore, geometric and non-geometric properties of the slab module are assigned.

The fastening system is also created as a flexible recurring module with both geometric and non-geometric information. Some of these data are associated to the products ETA. As mentioned above, critical for the design are the actions on the fastening resulting from the kinematic history of the fixed element (robot). The movement of the robot and object happens elliptical in space, i.e. a complete rotation around its own axis with vertical displacement of the robot arm (see also Fig. 3). The fatigue assessment is then carried out for 1 million cycles, representing the service life of the robot.

The robot used in this case study, is Motoman MH50 II of Yaskawa. The robot coding data are conveyed to the BIM model which is then connected to the fastening technology design algorithm in order to provide the automated dimensioning. A warning trigger is also be assigned for the case that the ultimate capacity limit state of the fastening system is approached, at a characteristic $75 \%$ by load cycles.
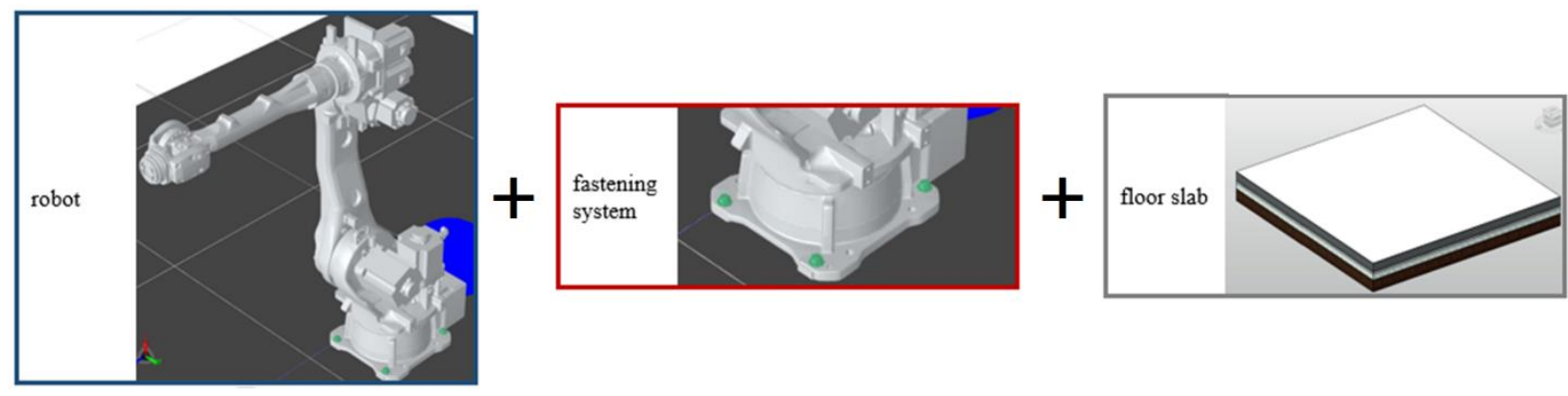

Fig. 2. Objects of investigation
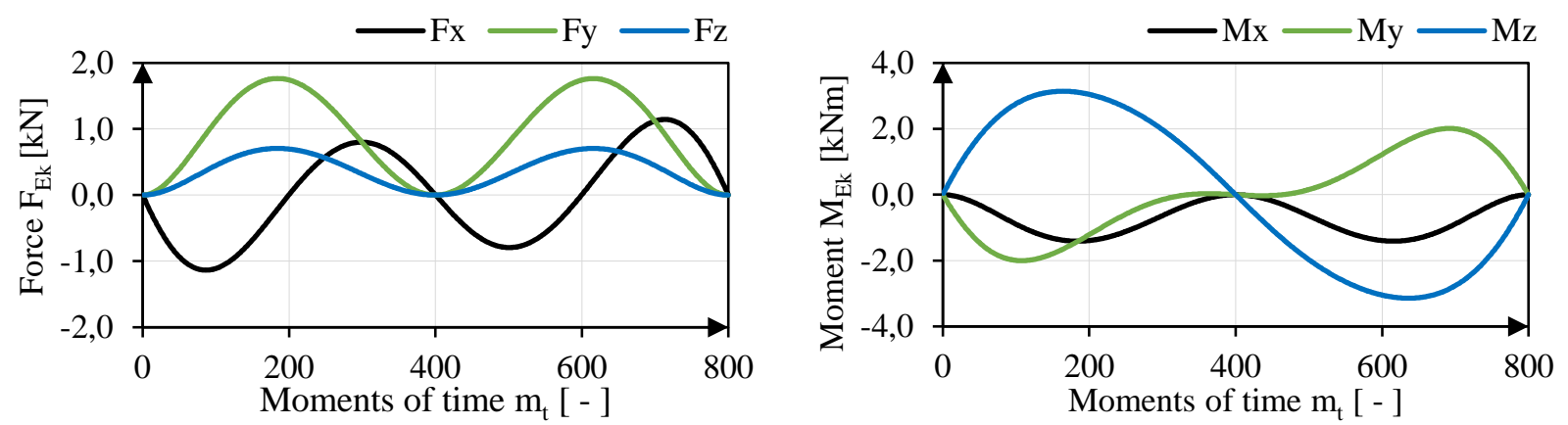

Fig. 3. Force (left side) and moment (right side) histories for the motion of the robot. Two cycles are define in this period of loading, from 1 to 400 and from 401 to 800 . 
Spyridis et al. / Proceedings of the Creative Construction Conference (2019) 117 https://doi.org/10.3311/CCC2019-117

Table 1. Summary of data related to the BIM model, distinguishing material and geometrical parameters used in the structural design (light green) and elements related to the production and the associated robot kinematics (dark blue).

\begin{tabular}{|c|c|c|c|c|c|}
\hline subsystem & name building part & building part ID & parameter & value & unit \\
\hline supply of the machine & factory area & electrical supply & installed load & 4,0 & kVA \\
\hline networking of the machines & factory area & data supply & $\#$ of data supplies & 1 & - \\
\hline networking of the machines & factory area & wireless lan & wireless lan available & affirmative & - \\
\hline supply of the machine & factory area & compressed air supply & compressed air supply necessary & negative & - \\
\hline supply of the machine & factory area & compressed air supply & compressed air & - & - \\
\hline fastening of machines & foundation area & fastening system & anchor diameter & 16 & $\mathrm{~mm}$ \\
\hline fastening of machines & foundation area & fastening system & borehole diameter & 18 & $\mathrm{~mm}$ \\
\hline fastening of machines & foundation area & fastening system & anchor embedment depth & 125 & $\mathrm{~mm}$ \\
\hline environment of the machines & factory area & heating / air-conditioning & maximum temperature & 45 & ${ }^{\circ} \mathrm{C}$ \\
\hline environment of the machines & factory area & heating / air-conditioning & minimum temperature & 0 & ${ }^{\circ} \mathrm{C}$ \\
\hline environment of the machines & factory area & heating / air-conditioning & maximum humidity & 80 & $\%$ \\
\hline environment of the machines & factory area & heating / air-conditioning & minimum humidity & 20 & $\%$ \\
\hline floor space of the machines & foundation area & floor slab & weight of the robot & 550 & $550 \mathrm{~kg}$ \\
\hline floor space of the machines & foundation area & floor slab & maximum load capacity & 50 & $50 \mathrm{~kg}$ \\
\hline floor space of the machines & foundation area & floor slab & MR maximum torque & 216 & $216 \mathrm{Nm}$ \\
\hline floor space of the machines & foundation area & floor slab & maximum moment of inertia & 28 & $28 \mathrm{~kg} \mathrm{x} \mathrm{m}^{2}$ \\
\hline floor space of the machines & foundation area & floor slab & concrete quality & $\mathrm{C} 30 / 37$ & - \\
\hline floor space of the machines & foundation area & floor slab & minimum width foundation & - & - \\
\hline floor space of the machines & foundation area & floor slab & minimum length foundation & - & - \\
\hline floor space of the machines & foundation area & floor slab & minimum thickness foundation & 160 & $\mathrm{~mm}$ \\
\hline floor space of the machines & foundation area & floor slab & minimum edge distance dowel & 210 & $\mathrm{~mm}$ \\
\hline floor space of the machines & foundation area & floor slab & concrete cover & 35 & $\mathrm{~mm}$ \\
\hline floor space of the machines & foundation area & floor slab & reinforcement spacing longitudinal & 150 & $\mathrm{~mm}$ \\
\hline floor space of the machines & foundation area & floor slab & reinforcement distance transverse & 150 & $\mathrm{~mm}$ \\
\hline floor space of the machines & foundation area & floor slab & reinforcement diameter & 10 & $\mathrm{~mm}$ \\
\hline floor space of the machines & foundation area & floor slab & reinforcement Steel grade & B500B & \\
\hline floor space of the machines & foundation area & floor slab & distributed load & 5 & $\mathrm{kN} / \mathrm{m}^{2}$ \\
\hline floor space of the machines & foundation area & floor slab & single loads & $7,5 / 216$ & $\mathrm{kN} / \mathrm{cm}^{2}$ \\
\hline floor space of the machines & foundation area & floor slab & evenness & DIN 18202 , table 3 , line 4 & - \\
\hline floor space of the machines & foundation area & floor slab & surface & smoothed & - \\
\hline
\end{tabular}

\section{Integration of asset, structural, and production data in a BIM-based design}

The calculation and processing of information of the action and characteristic values of the fastening system in the current design models and concepts is based on simple empirical/physical equations, which require a certain level of engineering knowledge and define many sub-cases for correspondingly limited and special design cases. A generally valid design under consideration of various possible boundary conditions is not feasible. The advanced design concept, used in this case study, for a fastening systems under fatigue-relevant loading covers for the generic or initially random nature of the actions, and it allows for a time-independent and multi-dimensional design. This is realized by a transformation to utilization levels with the high combinatory of various time considerations, so that also an integration to BIM compatible data formats is possible. For the analysis of different design situations, the force and moment 
Spyridis et al. / Proceedings of the Creative Construction Conference (2019) 117

https://doi.org/10.3311/CCC2019-117

information from Table 1 and Fig. 3, is used as the basis for describing the motion sequence with the real actions. In comparison to these exact courses, approximations are also used and analysed in the form of sinusoidal functions. Here, the minimum and maximum points in the sinusoidal course are determined equivalent to the extreme values of the real action. A further variation in the investigation of the design concepts is the number of differentiated time moments. In this study, 30, 60, 90, 240 and 360 values are also used and examined. The influence of this design option is to be carried out and analyzed with the comparison between the separate consideration of both cycles and the conventional duplication of the unfavorable course. The design check has indicated the most unfavourable design situations, so that on the one hand for steel failure a higher utilization results by conventional designing with 1 loadcycle ( 1 to 400 or 401 to 800 ) and the double number of cycles. The variant with previous approximation with sinusoidal functions shows a reduction of the steel failure and a significant increase in the case of concrete failure.

\section{Conclusion and outlook}

The support of a BIM-model in the design process of fastening systems offers the advantage of an automated and realtime based evaluation of the selection of fastening systems. Interactions and boundary conditions (conflicts) can also be automatically checked. Structural information must be digitised from ETAs in advance, in order to enable processing of quantitative and qualitative values. Furthermore, efficient and user-friendly program structures and software solutions must be developed to be able to process this information in fast computing processes. The categorisation and integration of data is showcased herein. This conceptual process is further proposed and a design example is also shown in order to verify the feasibility of the concept, with focus on life cycle relevant design situations.

An approach for automatic integration of various program sequences into a BIM model could be prospectively based on the solution for flexible robot programming via drag and drop (also refer to the example in [9]). This solution enables a new form of robot programming, so that the functions and program sequences of the robot can be easily defined via a modular system, independent of manufacturers and without programming knowledge of the user. This concept offers the potential to harmonize the problem of differences in programming and could thus offer an efficient interface to a BIM model for the automatized capturing of data from the production program. Conveyed to a Industry 4.0 environment, the planning and facility management exercises, assisted by sensors and programmed warning features can allow for a full integration of asset and production management.

\section{References}

[1] M. Gralla, L. Lenz, Digitalisierung im Baubetrieb - Building Information Modeling und virtuelle Zwillinge. in: Festschrift für Prof. Motzko 2017, Darmstadt, Germany, 2017, pp. 210.

[2] L.T. Lenz, M. Gralla, M. Hoepfner, P. Spyridis, K.C. Weist, BIM approach for automatic decision support: case study fastening systems in factory adaptation planning, in European Conference on Computing in Construction, Chania Crete, Greece, 2019. https://doi.org/10.35490/EC3.2019.136

[3] BIMS-US (2019) Available: https://www.nationalbimstandard.org/ about, Accessed: 24-Feb.-2019.

[4] R. Wendner, C. Peitner, P. Spyridis, P. Life-cycle robustness of fastening technology: A Christian Doppler Laboratory. Sonderheft: Werkstoffe und Konstruktionen - Innovative Ansätze / Beton- und Stahlbetonbau 108 (2013): 121-128.

[5] K. C. Weist, BIM im Bauprozessmanagement - Entwicklung einer Datenbasis für die modellbasierte Ablaufplanung und Kalkulation, Dortmund, Germany, 2019, p. 48

[6] Comité Européen de Normalisation (CEN), EN 1992-4. Eurocode 2:2018, Design of concrete structures - Part 4: Design of fastenings for use in concrete. Brussels, Belgium, CEN, 2018

[7] E. Scheller, J. Künzlen, Handbuch der Dübeltechnik,Swiridoff Verlag, Künzelsau 2013

[8] K.Block , F. Dreier, DAfStb-Heft 541: Das Ermüdungsverhalten von Dübelbefestigungen, Beuth Verlag, Berlin 2003

[9] D. Seebauer, Roboterprogrammierung via Drag-and-Drop, in: productronic, Hüthig, Heidelberg, 01.02.2019, pp. 48-49. 